\title{
Central Bank Digital Currencies: A Bibliometric Analysis
}

\author{
Elisabeta Pana \\ Central Connecticut State University
}

Rapid technological advances in electronic money and payment methods entice central banks to consider their role in an ever more digital world. Transformative changes to the financial and monetary system are met with an array of policy responses, including the issuance of central bank digital currencies. This paper examines the trends in the evolution of central bank digital currency literature and identifies the important features of the research area. A bibliometric analysis was used to analyze 77 journal articles on central bank digital currencies published from 2018 to 2020 in Scopus Database. Through performance, cocitation, and co-word analysis of the retrieved literature, we document the main journals, countries, authors, and emerging fields of research in central bank digital currencies.

Keywords: bibliometric citation analysis, Central Bank digital currency, Central Bank, money

\section{INTRODUCTION}

As the ongoing digital revolution is spurring new forms of digital currencies, central banks are compelled to explore the adoption of central bank digital currencies (CBDCs). CBDCs represent fiat currency issued by central banks in digital form, a third form of base money akin reserves and banknotes (Kumhof and Noone, 2018; Allen et al., 2020). The rise of cryptocurrencies has been met with increased concerns about their impact on monetary policy, the stability of the financial system, and the central bank's exclusive right to issue base money (Nabilou, 2020). While central banks have more than a few regulatory, supervisory, and oversight tools to influence the development and acceptance of cryptocurrency, the merits of issuing CBDCs as a policy response have been at the center of debate among academics and policymakers.

Notwithstanding a growing CBDCs literature on topics ranging from the underlying technology to their impact on the financial system, many important research questions remain (Carapella and Flemming, 2020). Bibliometric analysis provides a quantitative approach to identify the research questions, influential aspects of the literature, and evolution trends through mathematical and statistical methods. Bibliometric analysis complements the narrative literature surveys, common in the finance literature, by providing a more comprehensive understanding of the knowledge in the field. An increased interest in employing different methodologies to conduct literature review studies in finance is reflected by the recent adoption of quantitative-qualitative surveys, bibliometric, and content analysis (Bahoo, Alon, and Paltrinieri, 2020; Goodell, 2019; Jiménez and Bjorvatn, 2018; Kyriazis, Papadamou, and Corbet, 2020; Paltrinieri et al., 2019; Zamore et al., 2018). This new approach is particularly important, as it can be "the most powerful tool to inform academics, professionals and policy-makers about the current state of knowledge, consensuses and ambiguities in the emerging discipline." (Corbert, Lucey, Urquhart, and Yarovaya, 2019). 
Following Bahoo et al. (2020) and Paltrinieri et al. (2021), we employ a bibliometric approach and add to the existing literature the results of a review of the CBDC research field and some of its more important features, such as the leading countries, journals, and authors.

\section{METHODOLOGY}

We start with a statistical analysis of the CBDC literature and then conduct a bibliometric analysis using co-citation and co-word methods (Liu et al., 2005; Zamore et al., 2018, Iddy and Alon, 2019). Fig. 1 provides a complete picture of the steps included in the methodology.

\section{FIGURE 1}

\section{METHODOLOGICAL APPROACH}

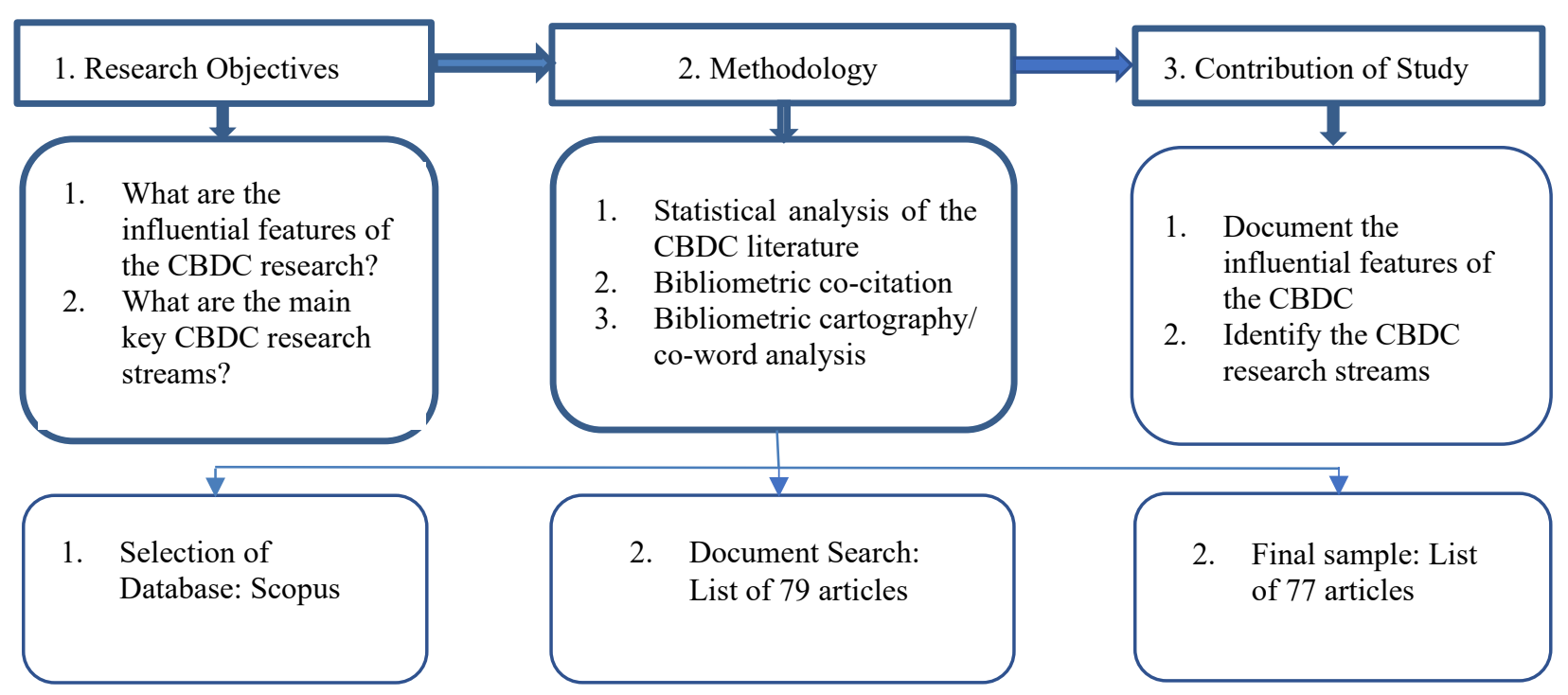

\section{Sample Selection Process}

Our sample selection process consists of two steps. The first step is the collection of the bibliometric data for the bibliometric citation analysis. We select Scopus database because it is a recognized index with a wide coverage of publications and provides reliable bibliographic data (Martin-Martin et al, 2018; Cintra et al., 2018; Muritala et al., 2020). We search the articles with keywords "central bank digital currency" and filtered the results to include only articles, resulting in 79 documents. The second step of the sample selection ensures the retention of the relevant articles. The titles and abstracts were reviewed, and we retained 77 articles with "central bank digital currency" as a direct subject of the study (Zott et al., 2011).

\section{Data Analysis}

The data analysis starts with the identification of the general trends in the CBDCs research area. Next, we conduct the bibliometric analysis, using the VOSviewer software. A powerful visualization software, VOSviewer uses a distance-based mapping technique and is more powerful in visualization than CiteSpace and Sci2 (Van Eck and Waltman, 2010; Van Eck and Waltman, 2014; Van Eck and Waltman, 2021). We start with a co-citation analysis to identify the most co-cited sources and authors by creating maps of the constructed networks of authors and journals. For example, on a network map for co-cited sources, two journals are located at a certain distance and connect through a link. The distance between two journals approximates the relatedness of the journals, with journals having stronger relatedness being located closer to each other (Van Eck and Waltman, 2021.) However, co-citation is not a permanent relationship, as both the distance and the strength of the link between two journals change over time, reflecting the evolution of 
the research area of study (Muritala et al., 2020). In addition to co-citation, we conduct a co-occurrence analysis to identify of the main research themes of the study area and a co-authorship analysis to detect the main research networks along different dimensions.

\section{RESULTS}

\section{General Trends}

Despite being a nascent area of research, CBDCs continue to attract a growing interest among researchers, as indicated by the growth in the number of published articles per year (Figure 2).

FIGURE 2

\section{NUMBER OF DOCUMENTS (YEARLY TREND)}

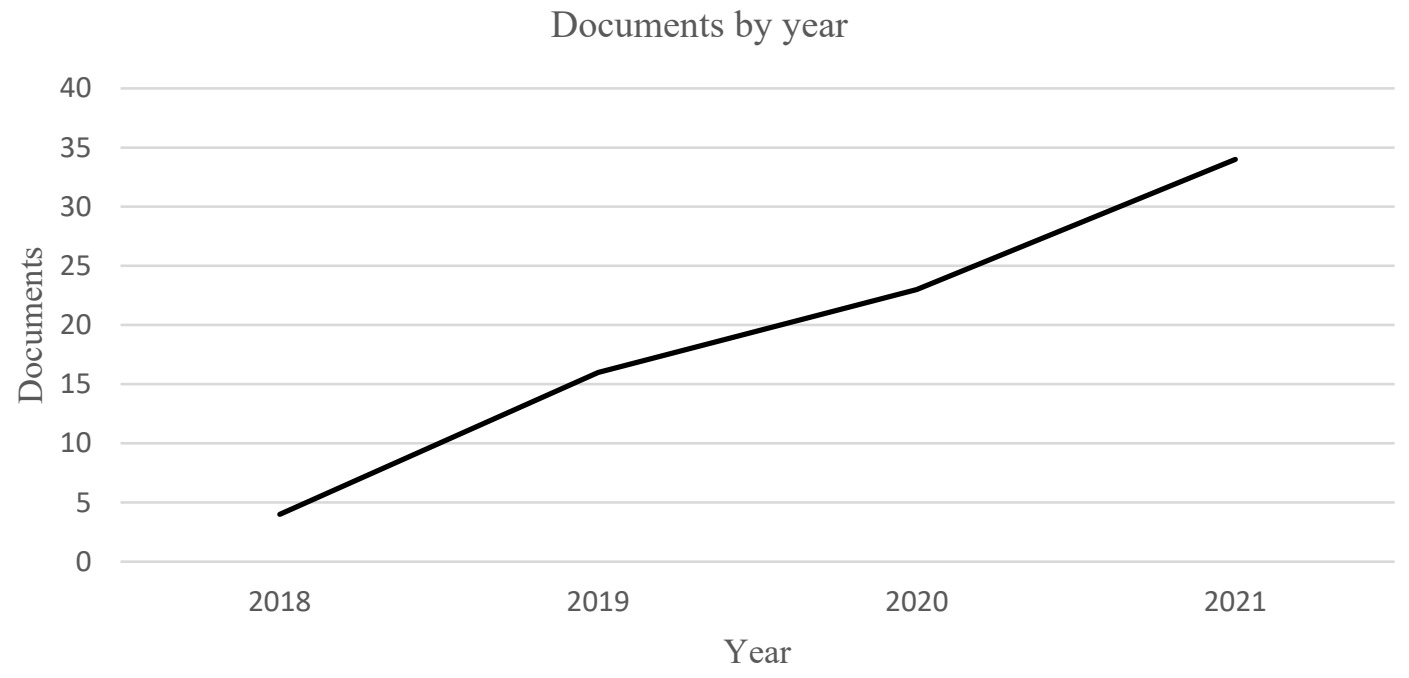

Table 1 shows the top six journals with the highest number of CBDC articles, using a threshold of three or more publications.

TABLE 1

TOP JOURNALS BASED ON NUMBER OF CBDC ARTICLES

\begin{tabular}{lrrrr}
\hline Journals & Articles & CiteScore 2020 & SJR 2020 & SNIP 2020 \\
\hline Journal of Payments Strategy and Systems & 11 & 0.5 & 0.219 & 0.276 \\
China Economic Journal & 5 & 1.3 & 0.380 & 0.611 \\
Sustainability Switzerland & 4 & 3.9 & 0.612 & 1.242 \\
Cato Journal & 3 & 0.8 & 0.299 & 0.685 \\
IEEE Access & 3 & 4.8 & 0.587 & 1.421 \\
Journal of Economic Dynamics and Control & 3 & 2.5 & 1.181 & 1.435 \\
\hline
\end{tabular}

For each journal, we report the CiteScore 2020, SJR 2020, and SNIP 2020. CiteScore 2020 counts the citations received in 2017-2020 to articles, reviews, conference papers, book chapters and data papers published in 2017-2020, and divides this by the number of publications published in 2017-2020.

We also identify the top ten influential countries in terms of number of publications with CBDC as a direct subject of study. We set the minimum criteria to three papers published by relevant countries. The top two countries are the United States and U.K. with 12 papers each, followed by China (9), Germany (7), Russian Federation (6), France (5), Spain (5), Switzerland (5), Canada (3), and South Korea (3) (Figure 3). 
FIGURE 3

TOP COUNTRIES BASED ON NUMBER OF PUBLISHED CBDC ARTICLES

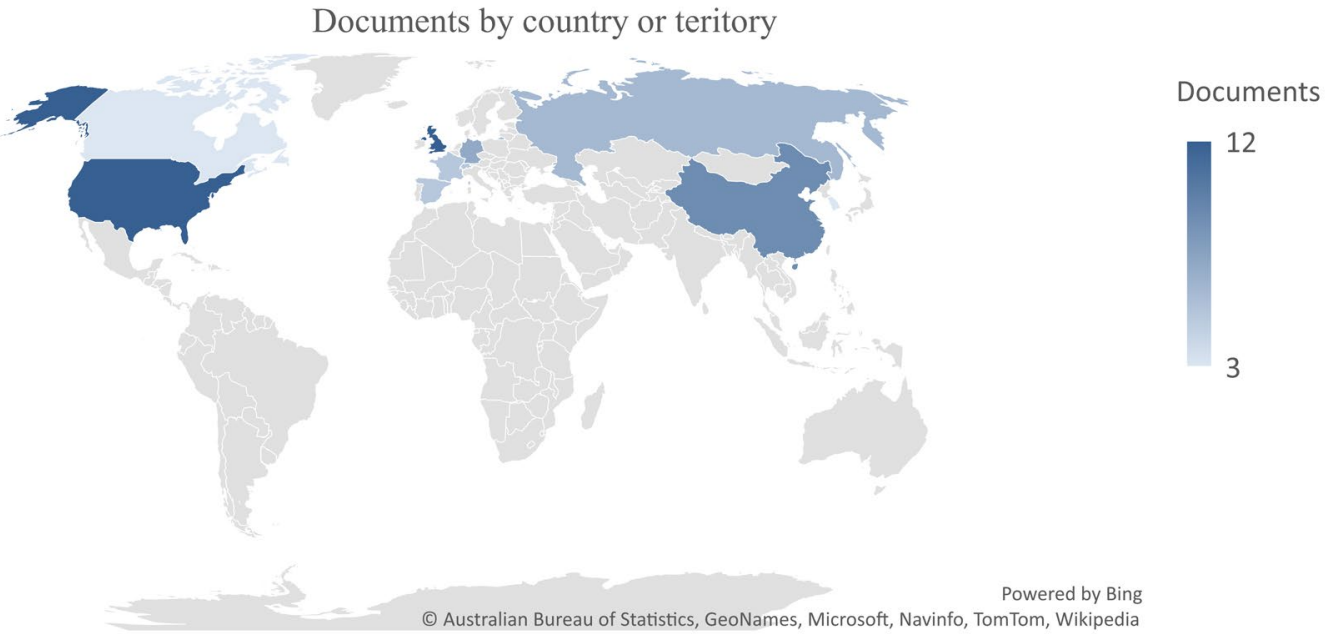

\section{Bibliometric Analysis}

We use the co-citation network map to identify the authors with a significant influence on the CBDCs area of research (Figure 4).

FIGURE 4

CO-CITATION ANALYSIS OVER 2018-2021 PERIOD IN CBDC LITERATURE

Sosviewer

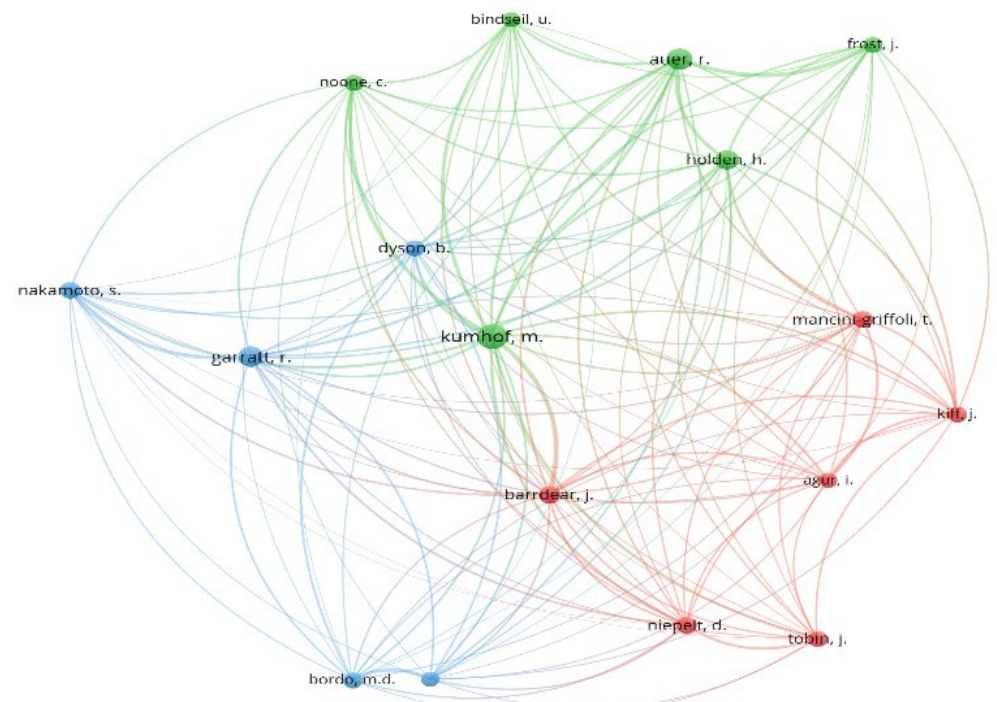

The unit of analysis is author, and the counting method is fractional counting. Figure 4 shows the cocitation network map whereas the nearness of two papers and the thickness of the lines connecting them approximate the strength of their co-citation links. Although these authors are not necessarily the most frequently cited in term of number of citations, they have been highly co-cited by the articles in final sample. We identify three different network clusters, with six authors in the first cluster (Augur, I, Barrdear, J., Kiff, J., Mancini-Griffoldi, T., and Tobin, J.), six authors in the second cluster (Auer, R., Bindseil, U., Frost, J., 
Holden, H., Kumhof, M., Noone, C.), and five authors in the third cluster (Bordo, M.D., Dyson, B., Garratt, R., Levin, A.T., and Nakamoto, S.).

The co-citation analysis using journals as the unit of analysis, and fractional counting as the counting method, identifies two main clusters (Figure 5).

\section{FIGURE 5 \\ CO-CITATION ANALYSIS OVER 2018-2021 PERIOD IN CBDC LITERATURE}

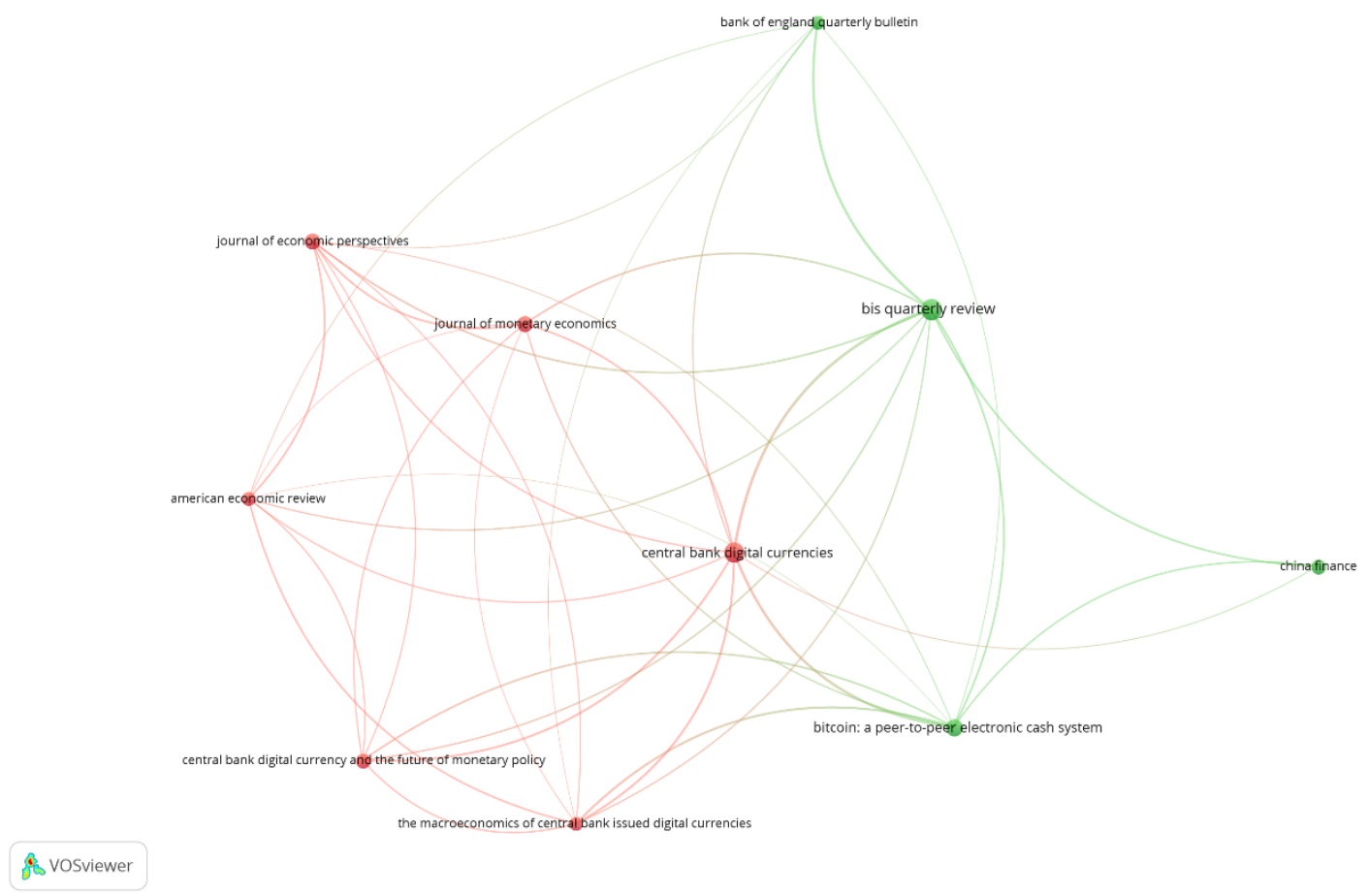

Similar to the argument made for the co-citation analysis based on authors, the journals in Figure 5's two clusters are not necessarily the most frequently cited in term of number of citations, but they have been highly co-cited by the articles our sample. The two clusters are clearly dominated by economics journals, with BIS quarterly Review and Bank of England Quarterly Bulletin having the strongest link. The top journals in terms of frequency are the BIS Quarterly Review and Journal of Monetary Economics.

We use the co-word analysis to identify the major CBDC research themes. To obtain the network map, we select co-occurrence as the type of analysis, the author keywords as the unit of analysis, fractional counting as the counting method, and set a threshold of three keyword occurrences. In a co-word analysis, articles with the same keywords are clustered together because keywords describe content (Ding, Chowdhury, and Foo, 2001).

Figure 6 shows three clusters or sub-fields, with the proximity of two keywords and the thickness of the lines connecting them approximating the frequently of co-occurrence and the size of a node approximating the frequency of occurrence of the keyword. The three clusters or subfields have a similar size. The top three keywords in terms of frequency are "central bank digital currency," "cbdc," "digital currency," "blockchain," and "monetary policy. The two keywords with the stronger connection are "central bank digital currency" and "blockchain." 
FIGURE 6

\section{CO-WORD ANALYSIS OVER 2018-2021 PERIOD IN CBDC LITERATURE}

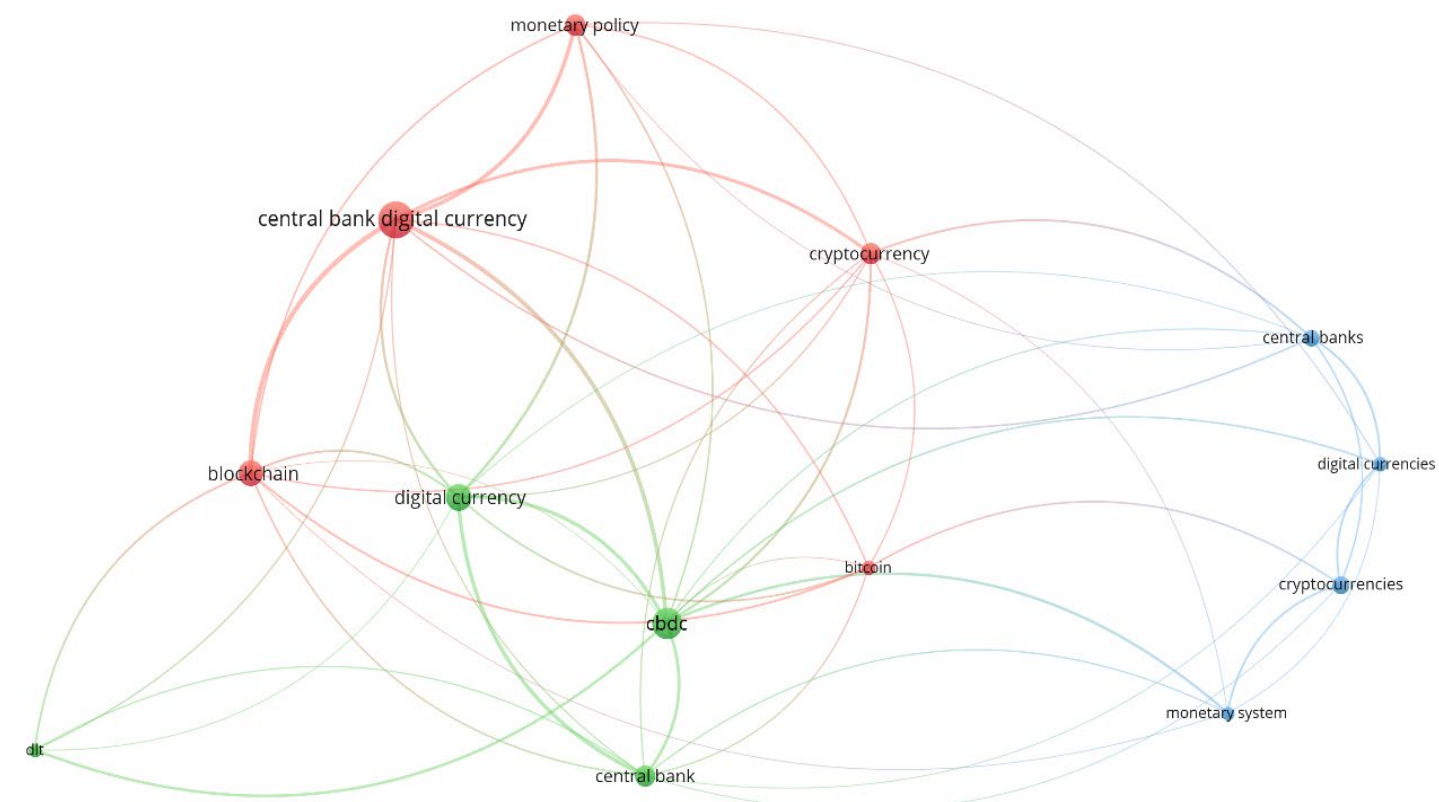

\& VOSviewer

\section{CONCLUDING REMARKS}

This study used a bibliometric analysis to review the research on CBDCs by analyzing a sample of 77 relevant articles retrieved from the Scopus database. We apply co-citation and co-word analyses to investigate the research streams or networks in the literatures and the trends in this field. The results provide an important quantitative addition to the existing literature and enhance the understanding of this burgeoning research area.

CBDCs have shown their fast and growing relevance. While recent literature is centered around economics journals, researchers in other areas are presented with opportunities for future developments. The impending implementation of central bank digital currencies will offer researchers in areas like business and finance the opportunity to study CBDCs from a different perspective.

\section{REFERENCES}

Allen, S., Čapkun, S., Eyal, I., Fanti, G., Ford, B.A., Grimmelmann, J., . . Zhanf, F. (2020). Design choices for central bank digital currency: Policy and technical considerations. Technical report, National Bureau of Economic Research.

Bahoo, S., Alon, I., \& Paltrinieri, A. (2020). Sovereign wealth funds: Past, present, and future. International Review of Financial Analysis, 67, 101418.

Carapella, F., \& Flemming, J. (2020). Central Bank Digital Currency: A Literature Review. Retrieved January 2021, from https://www.federalreserve.gov/econres/notes/fedsnotes/central-bank-digitalcurrency-a-literature-review-20201109.htm

Cintra, R.F., Cassol, A., Ribeiro, I., \& de Carvalho, A. O. (2018). Corruption and emerging markets: Systematic review of the most cited. Research in International Business and Finance, 45, 607619. 
Corbet, S., Lucey, B., Urquhart, A., \& Yarovaya, L. (2019). Cryptocurrencies as a financial asset: A systematic analysis. International Review of Financial Analysis, 62, 182-199.

Ding, Y., Chowdhury, G.G., \& Foo, S. (2001). Bibliometric cartography of information retrieval research by using co-word analysis. Information Processing and Management, 37(6), 817-842.

Gaur, A., \& Kumar, M. (2018). A systematic approach to conducting review studies: An assessment of content analysis in 25 years of IB research. Journal of World Business, 53(2), 280-289.

Goodell, J.W. (2019). Comparing normative institutionalism with intended rationality in cultural-finance research. International Review of Financial Analysis, 62, 124-134.

Iddy, J.J., \& Alon, I. (2019). Knowledge management in franchising: A research agenda. Journal of Knowledge Management, 24(2).

Jiménez, A., \& Bjorvatn, T. (2018). The building blocks of political risk research: A bibliometric cocitation analysis. International Journal of Emerging Markets, 13(4), 631-652.

Kumhof, M., \& Noone, C. (2018). Central bank digital currencies-Design principles and balance sheet implications. Bank of England working paper No. 725, 2018.

Kyriazis, N., Papadamou, S., \& Corbet, S. (2020). A systematic review of the bubble dynamics of cryptocurrency prices. Research in International Business and Finance, 101254.

Liu, X., Bollen, J., Nelson, M.L., \& Sompel, H.V.D. (2005). Co-authorship networks in the digital library research community. Information Processing \& Management, 41(6), 1462-1480.

Martín-Martín, A., Orduna-Malea, E., Thelwall, M., \& Delgado López-Cózar, E. (2018). Google Scholar,Web of Science, and Scopus: A systematic comparison of citations in 252 subject categories. Journal of Informetrics, 12, 1160-1177.

Muritala, B., Sánchez-Rebull, M-V., \& Hernandez, A. (2020). A Bibliometric Analysis of Online Reviews Research in Tourism and Hospitality. Sustainability, 12, 9977. doi:10.3390/su12239977

Nabilou, H. (2020). Testing the waters of the Rubicon: The European Central Bank and central bank digital currencies. Journal of Banking Regulation, 21, 299-314.

Paltrinieri, A., Hassan, M.K., Bahoo, S., \& Khan, A. (2019). A bibliometric review of sukuk literature. International Review of Economics \& Finance.

Valickova, P., Havranek, T., \& Horvath, R. (2015). Financial development and economic growth: A meta-analysis. Journal of Economic Surveys, 29(3), 506-526.

Van Eck, N.J., \& Waltman, L. (2010). Software survey: VOSviewer, a computer program for bibliometric mapping. Scientometrics, 84(2), 523-538.

Van Eck, N.J., \& Waltman, L. (2014). Visualizing bibliometric networks, measuring scholarly impact.

Van Eck, N.J., \& Waltman, L. (2021). VOSviewer Manual.

Van Eck, N.J., Waltman, L., Dekker, R., \& Van den Berg, J. (2010). A comparison of two techniques for bibliometric mapping: Multidimensional scaling and VOS. Journal of the American Society for Information Science and Technology, 61(12), 2405-2416.

Zamore, S., Djan, K.O., Alon, I., \& Hobdari, B. (2018). Credit risk research: Review and agenda. Emerging Markets Finance and Trade, 54(4), 811-835.

Zott, C., Amit, R., \& Massa, L. (2011). The business Model: Recent developments and future research. Journal of Management, 37(4), 1019-1042. 